\title{
Temperature and Wetness-Duration Requirements for Grape Leaf and Cane Infection by Phomopsis viticola
}

O. Erincik and L. V. Madden, Department of Plant Pathology, D. C. Ferree, Horticulture and Crop Science, and M. A. Ellis, Department of Plant Pathology, The Ohio State University, Wooster 44691

\begin{abstract}
Erincik, O., Madden, L. V., Ferree, D. C., and Ellis, M. A. 2003. Temperature and wetness-duration requirements for grape leaf and cane infection by Phomopsis viticola. Plant Dis. 87:832840 .

In 1998 and 1999, controlled-environment studies were conducted in growth chambers to determine the temperature and wetness-duration parameters required for leaf and cane infection of grape by Phomopsis viticola. Greenhouse-grown 'Catawba' (Vitis labrusca) and 'Seyval' (French hybrid) grapes were inoculated with $P$. viticola and incubated at constant temperatures of $5,10,15,20,25,30$, and $35^{\circ} \mathrm{C}$ and at wetness durations of $5,10,15$, and $20 \mathrm{~h}$ for each temperature. Data from each cultivar were analyzed by nonlinear regression analysis to determine the relationship between disease severity and temperature and wetness duration. A generalized form of the Analytis Beta model was found to provide the best fit to the data. Disease severity on leaves and canes increased with increasing wetness duration at most temperatures. Minimum and maximum temperatures for infection were around 5 and $35.5^{\circ} \mathrm{C}$, respectively. Optimum temperatures for leaf and cane infection were between 16 and $20^{\circ} \mathrm{C}$. In the 2000 and 2001 growing seasons, the generalized Beta model was validated in 'Catawba' and 'Seyval' vineyards by inoculating vines during natural rain events. Average temperature and hours of wetness for each event and inoculation were recorded and used in the model equation to predict disease severity on leaves and internodes. Correlation coefficients between observed disease severities following field inoculations and predicted disease severities for both cultivars were between 0.71 and 0.81 and always significant $(P<0.01)$. These results indicate that the model reliably predicted leaf and cane infection on both cultivars over a wide range of wetness durations and temperatures. The model may be useful in developing disease-forecasting systems for Phomopsis cane and leaf spot on grapes.
\end{abstract}

The incidence and severity of Phomopsis cane and leaf spot can vary greatly from season to season $(25,29)$. Seasonal differences in disease generally have been attributed to variability in environmental conditions such as rainfall and temperature (12,21-23,26,29), but little has been reported about the specific effects of environment on development of Phomopsis cane and leaf spot. It has been reported that disease incidence and severity are generally higher in wet growing seasons than in dry ones (29). Prolonged rainy weather, especially during early spring when young shoots are emerging, has been observed to be very conducive to infection (2,29). Hewitt and Pearson (14) associated early-season infections with low (presumably, below normal) temperatures during

Corresponding author: L. V. Madden E-mail: madden.1@osu.edu.

Salaries and research support were provided by state and federal funds appropriated to the Ohio Agricultural Research and Development Center (OARDC), The Ohio State University.

Accepted for publication 10 February 2003.

Publication no. D-2003-0428-04R

(C) 2003 The American Phytopathological Society this time. They stated that the fungus was active only at low temperature and, when that temperature increased, the fungus became inactive, resulting in no infection later in the growing season (14).

The effects of temperature and wetness duration on foliar infection by Phomopsis viticola were first studied by Bugaret (4) in 1984. He reported that the optimum temperature for infection was between 23 and $25^{\circ} \mathrm{C}$. He also reported that the average temperature recorded at bud break in the spring ranged from 8 to $18^{\circ} \mathrm{C}$, which is considerably lower than the optimum observed in his studies. He further reported that at least $4 \mathrm{~h}$ of wetness are required for infection to occur at the optimum temperature. These studies were conducted only on vinifera grapes (Vitis vinifera) using an isolate of $P$. viticola collected in France.

At present, timing of fungicide applications for controlling Phomopsis cane and leaf spot consists of one to two sprays early in the season (at 2.5 and $12.7 \mathrm{~cm}$ of shoot growth) and one to two sprays during bloom (14,24). These are protectant or prophylactic applications, with little or no consideration given to environmental factors required for disease development in relation to fungicide timing.

The effective use of disease forecasting or warning systems for timing of fungicide applications for controlling several plant diseases in Ohio has been demonstrated $(9,10,19)$. Often, depending upon weather conditions, the number of fungicide applications can be reduced while obtaining control equal to that obtained with a "fullseason" fungicide program based on spraying the crop at fixed growth stages or times during the growing season $(9,10,19)$. Temperature and wetness duration parameters for prediction of foliar infection of vinifera grapes by $P$. viticola have been reported in France $(4,5)$. These parameters have not been validated in North America, and there have been no studies conducted to determine temperature and wetness duration parameters required for infection of American grapes ( $V$. labrusca) or French hybrids (V. vinifera $\times$ non- $V$. vinifera species).

Further studies are necessary to more clearly define the effects of environmental factors on development of Phomopsis cane and leaf spot. Information on the effect of temperature and wetness duration on infection by $P$. viticola would provide a better understanding of disease biology, and could be useful in the development of predictive or forecasting systems for the disease. An effective disease forecasting system could be used by growers to more accurately time fungicide applications for controlling the disease, and may result in fewer fungicide applications in dry growing seasons.

The objectives of this study were to (i) determine temperature and wetness-duration parameters required for grape leaf and cane infection of a French hybrid and an American grape cultivar (V. labrusca) by $P$. viticola, (ii) develop a model for Phomopsis cane and leaf spot infection using the information obtained under objective $i$, and (iii) validate the model developed under objective ii, through the use of inoculations of grapes during natural rain events in the field.

\section{MATERIALS AND METHODS}

Controlled environmental studies. Symptomless cane cuttings were collected from dormant, field-grown 'Seyval' ( $V$. vinifera $\times V$. rupestris $\times V$. aestivalis $)$ and 'Catawba' (V. labrusca) plants during February 1998. Dormant cuttings were placed in a misted cutting bed and allowed to grow roots. Rooted plants were transplanted into a mixture of peat, steam-disinfected loam, and perlite $(1: 1: 1, \mathrm{vol} / \mathrm{vol})$ in $15-\mathrm{cm}$ pots. Each plant was trained to a 
single shoot and allowed to grow in the greenhouse until they had at least six leaves. Plants were fertilized with $13 \mathrm{~g}$ of osmocote (14-14-14) every-other month, and were watered as needed with deionized water. The four youngest leaves and internodes per shoot were tagged for inoculation with $P$. viticola.

The isolate of $P$. viticola used in previous studies (11) also was used for this study. The isolate was maintained by inoculating surface-disinfected disks cut from mature grape berries ('Thompson Seedless') placed on potato-dextrose agar (PDA) (11). Plugs cut from the edge of actively growing mycelia were placed in the center of each grape disk, and the pathogen was reisolated from PDA after it had grown through the disk. This procedure, aimed at maintaining pathogenicity, was repeated every month during the time period that inoculations were being made. Cultures were grown on PDA in petri plates at $21^{\circ} \mathrm{C}$ under continuous fluorescent light at $58 \mu \mathrm{E} \mathrm{m} \mathrm{m}^{-2} \mathrm{~s}^{-1}$ for 15 to 20 days. Conidia were collected by flooding culture plates with sterile deionized water. Pycnidia and conidia were detached by rubbing the surface with a paint brush. The suspension was filtered through four layers of cheesecloth, and was adjusted to $1 \times 10^{7}$ conidia (alpha spores) per milliliter using a hemacytometer. The same isolate was used for all experiments.

The conidial suspension was sprayed by using an atomizer onto previously tagged leaves and internodes until runoff. Inoculated plants were placed into a controlledenvironment chamber (CEC; Rheem Manufacturing Company, Asheville, NC) maintained at a constant temperature under continuous wetness and light at $110 \mu \mathrm{E} \mathrm{m}^{-2}$ $\mathrm{s}^{-1}$. Inside the chamber, plants were kept in a plastic-covered wooden frame mist chamber containing two Hermidifier misters (Hermidifier Co. Lancaster, PA). Temperature and surface wetness inside the chamber were continuously monitored by thermistors (Model 101; Campbell Scientific, Logan, UT) and printed-circuit wetness sensors (Model 231; Campbell Scientific) interfaced to a microprocessor datalogger (Model 21-X; Campbell Scientific) for storage and later analysis. Five plants were randomly removed from the mist chamber at postinoculation times ranging from 5 to $20 \mathrm{~h}$ for each temperature tested. After removal, plants were immediately placed in a similar chamber without free moisture (drying chamber) and maintained at the same temperature and light until all plant parts were dry. A wetness sensor, located in the drying chamber, was sprayed with deionized water when plants were placed in the chamber to estimate surface drying time in this chamber. Drying time was added to the wetness duration in the mist chamber to determine total wetness duration. After drying, inoculated plants were placed in a growth chamber at $20^{\circ} \mathrm{C}$ for 7 days. Plants then were moved to a greenhouse and watered on the soil surface to avoiding wetting leaves and internodes.

Inoculations were conducted at temperatures of $5,10,15,20,25,30$, and $35^{\circ} \mathrm{C}$ and wetness duration of $5,10,15$, and $20 \mathrm{~h}$ at each temperature. A total of five plants for each wetness period and temperature combination were used. All inoculations were repeated a total of three times. The experimental design was a repeated measures, with temperature and cultivar as the whole plots and wetness duration as the repeated measure.

Disease severity on leaves was assessed by estimating the number of lesions on each of four tagged leaves per plant at 15 days after inoculations. The following rating scale was used: $0=$ no lesions, $1=0$ to 9 lesions per leaf, $2=10$ to 24 lesions per leaf, $3=25$ to 49 lesions per leaf, $4=$ 50 to 74 lesions per leaf, $5=75$ to 99 lesions per leaf, and $6=100$ or more lesions per leaf. Disease severity on internodes was assessed by estimating the proportion of the area covered by lesions on the four tagged internodes per plant at 30 days after inoculation. Disease severity was assessed by using the Horsfall-Barratt scale for disease assessment (15). For analysis purposes, the midpoint of the severity range for the Horsfall-Barratt rating and midpoint of the lesion-count range for the leaf rating were used for each individual leaf and internode section.

Data analysis and model development. Regression analysis was used in order to (i) determine if temperature, wetness duration, and their interaction significantly affected lesion numbers on leaves and internode disease severity for the two cultivars; and (ii) determine the functional form of the relationship between lesion number and disease severity and the controlled environmental variables. Regression analysis was conducted separately for each grape cultivar tested. The leaf with the maximum number of lesions and the internode with highest level of disease severity from each plant were chosen and used for data analysis. Because of variation in susceptibility of plant tissue with age (tissues become more resistant with maturity), there was less variation in disease measures among plants based on the maximum per plant than with mean per plant in the controlled-environment study (L. V. Madden, unpublished). The five plants for each wetness duration and temperature combination were considered subsamples, and mean leaf and internode disease severity of the five-plant subsamples was determined for each wetness duration, temperature, cultivar, and experimental replication combination prior to regression analysis. Both separate and combined analysis of the three replications for each cultivar were conducted.

Two types of models were evaluated using the data: (i) a logistic model and (ii) a generalized form of the Analytis Beta model $(1,13)$. The logistic model can be written in the form:

$\ln (Y /[K-Y])=f(T, W)$

(eq. 1)

in which $Y$ is either lesion numbers or internode disease severity, $W$ is wetness duration (h), $T$ is temperature $\left({ }^{\circ} \mathrm{C}\right), \ln (Y /[K$ $-Y]$ ) is the logit transformation of $Y, K$ is maximum disease (assumed to be $100 \%$ for internode severity and 150 lesions for lesion number per leaf), and $f(T, W)$ is a linear function consisting of a summation of terms involving parameters multiplied by powers of $T$ and $W$ (e.g., $T, T^{2}, W T$, $W T^{2}$, and so on) $(6,7,13)$. The second model, the generalized Beta model, can be written in the form (13):

$Y=\alpha t^{\beta}(1-t)^{\gamma} W^{\delta}$

in which $Y$ and $W$ are as defined above, $\alpha$, $\beta, \gamma$, and $\delta$ are unknown parameters estimated from data, and $t$ equals ( $T$ $\left.T_{\min }\right) /\left(T_{\max }-T_{\min }\right)$, which is a scaled version of temperature defined with the minimum and maximum temperatures for infection $\left(T_{\min }\right.$ and $T_{\max }$, respectively). The parameter $\beta$ describes how steeply $Y$ increases with increasing $T$ up to the optimum; the parameter $\gamma$ describes how steeply $Y$ decreases as $T$ increases past the optimum. Equation 2 can be linearized to:

$$
\begin{aligned}
\log (Y)= & \log (\alpha)+\beta \log (t)+ \\
& \gamma \log (1-t)+\delta \log (W)
\end{aligned}
$$

Models were evaluated using (i) coefficient of determination $\left(R^{2}\right)$, (ii) mean square error (MSE), and (iii) residual plots (7).

Field validation studies. In order to validate results from studies in controlled environment chambers, field studies were conducted on Seyval and Catawba vines during the 2000 and 2001 growing seasons. The Catawba vineyard was located at Snyder farm and the Seyval vineyard at Horticulture Unit II, both at the Ohio Agricultural Research and Development Center (OARDC), Wooster, OH. Vineyards were more than 4 years old. For each inoculation, a vine at each location was randomly selected shortly before inoculation, and 10 shoots were randomly selected from this vine. The four youngest leaves and internodes from the tip of each shoot were tagged. These leaves and internodes were inoculated by spraying with a conidial suspension of $P$. viticola $\left(1 \times 10^{7}\right.$ alpha conidia/ml) during a rain event. The same isolate used in the controlled-environment study was used for field validation. Procedures for maintaining the isolate were also the same. The suspension was sprayed to run-off using a single hand-held sprayer. Another vine at each location was randomly selected to serve as a control and to determine the level of natural infection by $P$. viticola. Leaves and internodes were tagged as previously described. The control vine was sprayed with sterile-deionized water only. 
Temperature, surface wetness, and rainfall at each location were monitored continuously with electronic sensors. A temperature sensor (Model 107; Campbell Scientific) and a wetness sensor (Model 237; Campbell Scientific) were placed 1.3 $\mathrm{m}$ above ground on the second wire of an Umbrella Kniffen training system. The sensors were placed so that they would be within the leaf canopy as sufficient foliage developed. Another temperature sensor and leaf wetness sensor of the same models were placed outside of the canopy. A tipping-bucket rain gage (Model TE525; Campbell Scientific) was placed $70 \mathrm{~cm}$ above of plant canopy to measure rainfall at each vineyard. All sensors were attached to a microprocessor datalogger (Model 21X; Campbell Scientific) as previously described. Inoculations were initiated on the first rainy day after vine-growth reached the Eichhorn-Lorenz growth stage 09 (at least two or three leaves unfolded) $(8,21)$. Inoculations were repeated during various rain events throughout the growing season until shoot tip growth terminated. The first inoculation for each growing season was conducted on 4 May and 27 April in 2000 and 2001, respectively. The last inoculation was conducted on 29 July and 17 July in 2000 and 2001, respectively. A total of 19 inoculations were conducted at each vineyard in 2000. In 2001, 18 and 17 inoculations were conducted in the Catawba and Seyval vineyards, respectively.

Weather data were recorded at 5-min intervals. Hours of wetness were determined as the time period from time of inoculation until leaves were completely dry. If the dry period between two wetness events was less than $6 \mathrm{~h}$, the two wetness events were combined and considered as a single event. Based on field observations over several years, the 6-h dry period has been incorporated into field-based forecasting systems for grape diseases in Ohio (10). Disease severity on leaves and internodes was assessed at 15 and 30 days after inoculation, respectively, as previously described in controlled-environment studies.

Analysis of field data. The mean was determined across the 10 shoots per vine of number of lesions per leaf and internode disease severity. These means served as observed disease intensities $(Z)$ for each field inoculation.

The model that best fit the controlledenvironment data was used to predict leaf and internode infection by $P$. viticola in field validation studies. Average temperature and hours of wetness for each inoculation were used in the equation of the model (e.g., equations 1 or 2 ) to predict numbers of lesions on leaves and disease severity on internodes $(Y \mathrm{~s})$. The Pearson correlation coefficients $(r \mathrm{~s})$ between observed disease values $(Z)$ and predicted values $(Y)$ were determined and used to assess the agreement between model predictions of disease and field observations.

To determine if predictions of leaf or internode disease intensity could be improved with use of monitored environmental data not utilized in the controlledenvironment-based model, or use of monitored environmental data in a form different from that used in the controlled-environment-based model, a stepwise multiple regression procedure was used. In particular, it was determined if observed disease
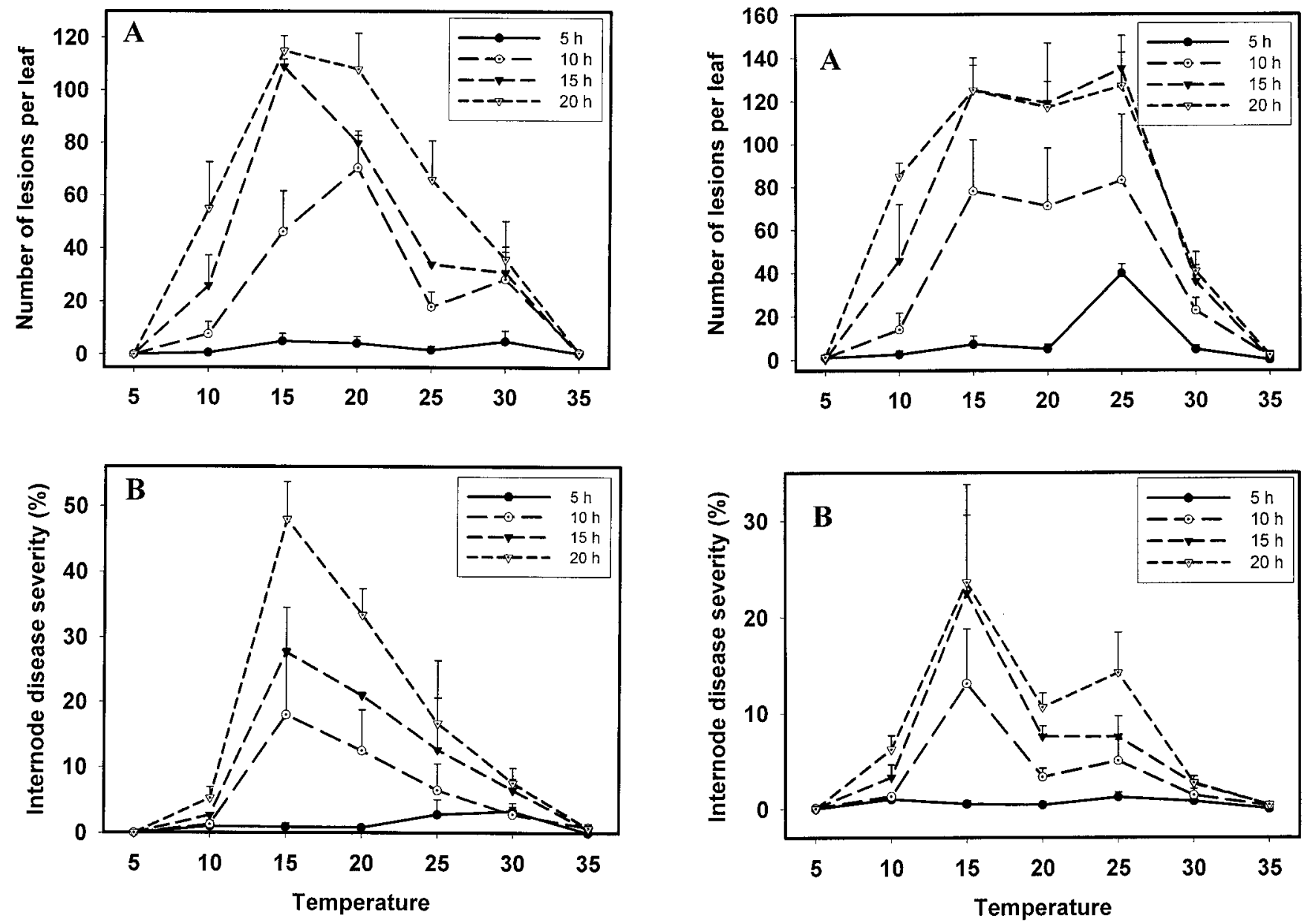

Fig. 1. Effect of temperature and wetness duration on disease severity on A, leaf and $\mathbf{B}$, cane tissues on 'Catawba' grapes in controlled-environment studies. $\mathbf{A}$, Curves represent the mean number of lesions per leaf at temperatures between 5 and $35^{\circ} \mathrm{C}$ with wetness durations of $5,10,15$, and $20 \mathrm{~h}$. B, Curves represent the mean percentage diseased area per internode at temperature between 5 and $35^{\circ} \mathrm{C}$ with wetness durations of $5,10,15$, and $20 \mathrm{~h}$.

Fig. 2. Effect of temperature and wetness duration on disease severity on A, leaf and $\mathbf{B}$, cane tissues on 'Seyval' grapes in controlled environment studies. A, Curves represent the mean number of lesions per leaf at temperatures between 5 and $35^{\circ} \mathrm{C}$ with wetness durations of $5,10,15$, and $20 \mathrm{~h}$. B, Curves represent the mean percentage diseased area per internode at temperatures between 5 and $35^{\circ} \mathrm{C}$ with wetness duration of $5,10,15$, and $20 \mathrm{~h}$. 
in the field $(Z)$ could be described with a model of the following form:

$Z=b_{0}+b_{1} Y+b_{2} X_{1}+b_{3} X_{2}+\ldots$

in which $X_{1}$ and $X_{2}$ represent two possible predictor (environmental) variables, and the $b$ s are parameters estimated with least squares regression. Predictor variables $(X)$ assessed were: duration of wetness (h), mean temperature during the wetness event $\left({ }^{\circ} \mathrm{C}\right)$, amount of rainfall $(\mathrm{mm})$, duration of rainfall (h), light code for time of inoculation ( 1 if in daylight and 0 if at night), and the interactions (products) of these variables. The predicted disease value based on use of the model from the controlled-environment study (which used the temperature and wetness duration information in one specific form $(Y)$ (e.g., equation 2) was included first in the stepwise procedure, and then the other variables were evaluated for inclusion in the empirical multiple regression model. Although $Y$ includes both wetness duration and temperature in one specific nonlinear form (e.g., equation 2), the stepwise regression procedure considered these variables in a linear manner. A forwardselection stepwise method was utilized, and selection of variables was based on $F$ tests.

\section{RESULTS}

Leaf and internode controlled-environment inoculations. Little or no disease developed on leaves and internodes of Catawba vines inoculated at temperatures of 5 and $35^{\circ} \mathrm{C}$ at any of the wetness durations tested (at 5, 10, 15, and $20 \mathrm{~h}$ of wetness) (Fig. 1). At these two extreme temperatures, the mean number of lesions per leaf ranged from 0 to 0.7 (Fig. 1A) and the mean of internode disease severity ranged from 0 to $0.8 \%$ (Fig. 1B). There was an increase in both number of lesions per leaf and disease severity on internodes at temperatures between 10 and $30^{\circ} \mathrm{C}$ when hours of wetness were increased (Fig. 1). For instance, at $15^{\circ} \mathrm{C}$, the mean number of lesions on leaves increased from 5 at $5 \mathrm{~h}$ of wetness to 115 at $20 \mathrm{~h}$ of wetness. At the same temperature, the mean disease severity on internodes increased from $0.9 \%$ at 5 $\mathrm{h}$ of wetness to $48 \%$ at $20 \mathrm{~h}$ of wetness. The highest number of lesions on leaves and the highest disease severity on internodes were obtained at $20 \mathrm{~h}$ of wetness duration at temperatures between 15 and $25^{\circ} \mathrm{C}$ (Fig. 1).

Results for Seyval inoculations in controlled-environment studies were similar to those obtained for Catawba. There was little or no disease on leaves and internodes inoculated at temperatures of 5 and $35^{\circ} \mathrm{C}$ at any wetness duration tested (Fig. 2). At these extreme temperatures, the mean number of lesions per leaf ranged from 0 to 2.2 (Fig. 2A) and the mean internode disease severity ranged from 0 to $0.4 \%$ (Fig. 2B). There was an increase in both number of lesions on leaves and disease severity on internodes at temperatures between 10 and $30^{\circ} \mathrm{C}$ when hours of wetness were increased from 5 to 15 (Fig. 2). For instance, at $15^{\circ} \mathrm{C}$, mean number of lesions on leaves increased from 7 at $5 \mathrm{~h}$ of wetness to 125 at $15 \mathrm{~h}$ of wetness. At the same temperature, internode disease severity on Seyval increased from $0.5 \%$ at $5 \mathrm{~h}$ of wetness to $22.5 \%$ at $15 \mathrm{~h}$ of wetness. When the hours of wetness were increased from 15 to 20 , there was little change in the mean number of lesions on leaves and mean disease severity on internodes for some temperatures (Fig. 2). For instance, at $15^{\circ} \mathrm{C}$, the mean number of lesions on leaves at 15 and $20 \mathrm{~h}$ of wetness duration was 125 . At $15^{\circ} \mathrm{C}$, the mean disease severity on internodes was 23 and $24 \%$ at wetness duration of 15 and $20 \mathrm{~h}$, respectively.

Data analysis and model development. The generalized form of Analytis Beta model (equation 2) was found to best fit the data from leaf and internode inoculations on both Catawba and Seyval in controlled-environment studies. Although $R^{2}$ and MSE values were similar between Beta and logistic models, the generalized Beta model was characterized by a more appropriate (i.e., random) residual plot (O. Erincik, unpublished). Residuals also had a normal distribution for the Beta model. To use the generalized Beta model, estimates of $T_{\min }$ and $T_{\max }$ are needed, which were not known before data collection. Based on Figures 1 and $2, T_{\min }$ was around $5^{\circ} \mathrm{C}$ and $T_{\max }$ was slightly above $35^{\circ} \mathrm{C}$. We used 4.95 and $35.5^{\circ} \mathrm{C}$ for $T_{\min }$ and $T_{\max }$, respectively.

The parameters of equation 3 were estimated from leaf and internode infection data separately for each of three replications for each cultivar (Tables 1 and 2). All estimated parameters were significantly different from $0(P<0.05)$. The model includes terms for temperature, wetness duration, and their product (equation 2), and estimated parameters were significantly greater than 0 ; therefore, these two environmental variables and their interaction affected disease intensity. An $F$ test indicated that there were no differences in regression results among the three replications $(P>0.05)$; therefore, data from the three replications could be combined. Although there were sometimes large differences in individual parameter estimates among replicates, the overall fit of the model to the data was similar for each replicate. Parameters were estimated from the combined data for overall means across replications, as well as pooled data (without consideration of replications; Tables 1 and 2).

Although the model fit both the means of the data and the pooled data, the best fit was obtained from data for means across replications. This is because there is only one value of $Y$ for each combination of $T$ and $W$, instead of three separate values (replications) with the mean data. For analysis based on means across replications, $R^{2}$ values were mostly greater than 0.80 (Tables 1 and 2). Parameter estimates for the means are used in all graphs and interpretations.

Optimum temperature $\left(T_{\text {opt }}\right)$ was estimated based on model parameters. As

Table 1. Estimated parameters from the generalized Beta model for temperature $(T)$ and wetness duration $(W)$ effects on number of lesions per leaf and internode disease severity caused by Phomopsis viticola on 'Catawba' grapes ${ }^{\mathrm{a}}$

\begin{tabular}{|c|c|c|c|c|c|c|c|}
\hline \multirow[b]{2}{*}{ Model } & \multicolumn{4}{|c|}{ Estimated parameters ${ }^{b}$} & \multirow[b]{2}{*}{ MSE } & \multirow[b]{2}{*}{ df } & \multirow[b]{2}{*}{$R^{2}$} \\
\hline & $\alpha^{\prime}$ & $\beta$ & $\gamma$ & $\delta$ & & & \\
\hline \multicolumn{8}{|l|}{ Leaf } \\
\hline Pooled & $1.50(0.283)$ & $1.78(0.278)$ & $2.43(0.358)$ & $1.42(0.168)$ & 336.4 & 77 & 0.77 \\
\hline Replication 1 & $0.80(0.237)$ & $1.16(0.226)$ & $1.28(0.228)$ & $1.56(0.185)$ & 116.8 & 24 & 0.88 \\
\hline Replication 2 & $0.50(0.301)$ & $1.31(0.301)$ & $2.16(0.418)$ & $1.99(0.288)$ & 159.5 & 24 & 0.91 \\
\hline Replication 3 & $3.88(0.858)$ & $4.26(1.12)$ & $5.79(1.48)$ & $0.99(0.261)$ & 499.7 & 24 & 0.79 \\
\hline Mean & $1.54(0.269)$ & $1.84(0.290)$ & $2.58(0.380)$ & $1.43(0.147)$ & 125.1 & 24 & 0.90 \\
\hline \multicolumn{8}{|l|}{ Internode } \\
\hline Pooled & $2.04(0.485)$ & $3.47(0.565)$ & $4.86(0.788)$ & $1.60(0.214)$ & 43.92 & 77 & 0.74 \\
\hline Replication 1 & $1.48(0.457)$ & $3.25(0.674)$ & $3.60(0.678)$ & $1.88(0.267)$ & 28.21 & 24 & 0.87 \\
\hline Replication 2 & $-0.22(0.648)$ & $1.74(0.480)$ & $1.86(0.498)$ & $2.22(0.445)$ & 28.92 & 24 & 0.81 \\
\hline Replication 3 & $5.85(1.29)$ & $8.21(1.75)$ & $12.12(2.46)$ & $1.41(0.159)$ & 7.93 & 24 & 0.95 \\
\hline Mean & $1.58(0.426)$ & $2.73(0.511)$ & $3.68(0.652)$ & $1.50(0.198)$ & 21.22 & 24 & 0.85 \\
\hline
\end{tabular}

${ }^{a}$ Mean square error (MSE), degrees of freedom (df), and coefficient determination $\left(R^{2}\right)$ are presented for each regression model. Analyses were done for each replication, for the pooled data, and for the means across replication for each $T$ and $W$ combination.

${ }^{\mathrm{b}}$ Estimated parameters from the generalized Beta Model: $\alpha^{\prime}$ corresponds to the log-transformed $\alpha, \beta$ and $\gamma$ correspond to temperature effect, and $\delta$ corresponds to wetness duration. Numbers in parentheses correspond to the standard deviation. 
described in Analytis (1), $t_{\text {opt }}$ can be defined as:

$t_{\text {opt }}=\beta /(\beta+\gamma)$

Based on the definition of $t, T_{o p t}$ is then calculated as $T_{\text {opt }}=t_{\text {opt }}\left(T_{\max }-T_{\min }\right)+T_{\min }$. For Catawba, $T_{o p t}$ was $17.7^{\circ} \mathrm{C}$ for lesions per leaf and $18.0^{\circ} \mathrm{C}$ for internode severity. For Seyval, $T_{o p t}$ was $20^{\circ} \mathrm{C}$ for lesions per leaf and $16.0^{\circ} \mathrm{C}$ for internode severity.

The estimated parameters from mean data for Catawba and Seyval were used in the generalized Beta model to predict lesions per leaf (YL) and disease severity on internodes (YI) at temperatures between 5 and $35^{\circ} \mathrm{C}$, at four different wetness durations $(5,10,15$, and $20 \mathrm{~h})$. An example graph is shown in Figure 3. Results were similar for both cultivars. Parameters then were used to predict the hours of wetness required for specific levels of leaf and cane infection by $\mathrm{P}$. viticola on Catawba and Seyval at a wide range of temperatures (Figs. 4 and 5). For example, in order to obtain 30 lesions per leaf on Catawba at the optimum temperature of $18^{\circ} \mathrm{C}$, at least $7.4 \mathrm{~h}$ of wetness were required (Fig. 4A). To obtain 120 lesions at the same temperature, $19.4 \mathrm{~h}$ of wetness were required. In order to obtain $5,10,20$, and $40 \%$ internode disease severity at the optimum temperature of $18^{\circ} \mathrm{C}, 4.8,7.6,12.1$, and $19 \mathrm{~h}$ of wetness were required, respectively (Fig. 4B). When temperature increased or decreased from the optimum, hours of wetness required for a given level of infection increased (Fig. 4). Results for Seyval were similar to those for Catawba. However, fewer than $5 \mathrm{~h}$ of wetness were required in order for 30 lesions per leaf to occur at temperatures between 15 and $24^{\circ} \mathrm{C}$ (Fig. 5A). To obtain 60,90 , and 120 lesions per leaf at $20^{\circ} \mathrm{C}$ required wetness durations of $8.2,12$, and $26 \mathrm{~h}$, respectively. To obtain 5,10 , and $20 \%$ disease severity on internodes at $17^{\circ} \mathrm{C}$ required wetness durations of 6,10 , and $18 \mathrm{~h}$, respectively (Fig. 5B).
Field validation studies. In 2000, wetness duration and average temperature for inoculations in the field ranged from 3.5 to $25.4 \mathrm{~h}$ and 12.4 to $23.2^{\circ} \mathrm{C}$, respectively, in the Seyval vineyard, and 3.5 to $21.7 \mathrm{~h}$ and 11.9 to $24^{\circ} \mathrm{C}$, respectively, in the Catawba vineyard. In 2001, wetness duration and average temperature for inoculations ranged from 1.4 to $16.8 \mathrm{~h}$ and 11.2 to $19.5^{\circ} \mathrm{C}$, respectively, in the Seyval vineyard; and 1.8 to $18.1 \mathrm{~h}$ and 11.6 to $23.3^{\circ} \mathrm{C}$, respectively, in the Catawba vineyard. Due to the presence of natural inoculum in both vineyards, some levels of Phomopsis cane and leaf spot developed on all inoculated and uninoculated vines in both vineyards and in both growing season. In most cases, disease severity on leaves and internodes of uninoculated vines was low. For example, mean lesion number per leaf and internode severity were $3.2(\mathrm{SE}=1.19)$ and $1.58 \%$ ( $\mathrm{SE}=0.57$ ), respectively, for $\mathrm{Ca}-$ tawba in 2000. Means in the control were always significantly less than disease severity on inoculated vines $(P<0.05)$ based on $t$ tests.

Wetness duration and average temperature for each inoculation were used in the equation of the generalized Beta model to predict the number of lesions per leaf and disease severity on internodes. Parameter estimates for the means of the replicates (Tables 1 and 2) were used in making all predictions. There was a significant correlation $(P<0.05)$ between observed disease $(Z$; either lesion number per leaf or internode severity) and predicted severity from the model ( $Y$; equation 2) (Figs. 6 and 7). There was mostly a positive (i.e., monotonically increasing) relationship between observed and predicted disease values. Except for one case (Fig. 6B) correlation coefficients were above 0.71, and half were above 0.80 . Generally, predictions for lesion number per leaf were slightly more accurate than the prediction

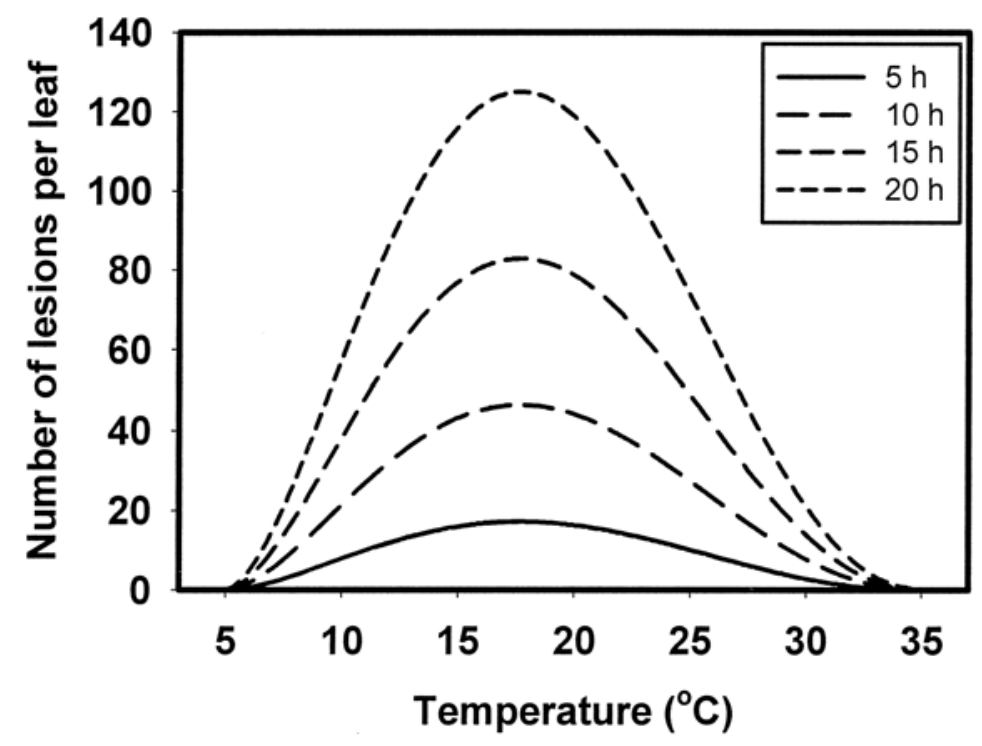

Fig. 3. Effect of temperature on predicted number of lesions per leaf on 'Catawba' inoculated with Phomopsis viticola at wetness durations between 5 and $20 \mathrm{~h}$. Curves were generated by using the parameters from the generalized Beta Model with values given in Table 1 for the mean data.

Table 2. Estimated parameters from the generalized Beta model for temperature $(T)$ and wetness duration $(W)$ effects on number of lesion per leaf and internode disease severity caused by Phomopsis viticola on 'Seyval' grapes ${ }^{\mathrm{a}}$

\begin{tabular}{|c|c|c|c|c|c|c|c|}
\hline & \multicolumn{4}{|c|}{ Estimated parameters $^{\mathbf{b}}$} & \multirow[b]{2}{*}{ MSE } & \multirow[b]{2}{*}{ df } & \multirow[b]{2}{*}{$R^{2}$} \\
\hline & $\alpha^{\prime}$ & $\beta$ & $\gamma$ & $\delta$ & & & \\
\hline \multicolumn{8}{|l|}{ Leaf } \\
\hline Pooled & $1.76(0.238)$ & $1.50(0.246)$ & $1.65(0.263)$ & $1.05(0.141)$ & 674.6 & 80 & 0.77 \\
\hline Replication 1 & $1.54(2.92)$ & $1.50(0.314)$ & $1.40(0.295)$ & $1.11(0.177)$ & 244.3 & 24 & 0.88 \\
\hline Replication 2 & $1.47(0.436)$ & $1.06(0.378)$ & $1.22(0.406)$ & $1.06(0.285)$ & 1009.6 & 24 & 0.71 \\
\hline Replication 3 & $2.58(0.386)$ & $2.38(0.450)$ & $2.79(0.531)$ & $0.97(0.186)$ & 544.2 & 24 & 0.86 \\
\hline Mean & $1.79(0.290)$ & $1.53(0.303)$ & $1.67(0.322)$ & $1.04(0.170)$ & 326.7 & 24 & 0.88 \\
\hline \multicolumn{8}{|l|}{ Internode } \\
\hline Pooled & $1.94(0.689)$ & $2.96(0.737)$ & $5.10(1.20)$ & $1.32(0.305)$ & 29.07 & 80 & 0.57 \\
\hline Replication 1 & $4.76(1.11)$ & $5.96(1.29)$ & $11.73(2.44)$ & $1.23(0.333)$ & 13.01 & 24 & 0.76 \\
\hline Replication 2 & $0.19(0.654)$ & $1.91(0.655)$ & $1.60(0.555)$ & $1.54(0.414)$ & 7.98 & 24 & 0.70 \\
\hline Replication 3 & $7.23(1.85)$ & $9.15(2.45)$ & $16.52(3.73)$ & $1.31(0.263)$ & 17.11 & 24 & 0.86 \\
\hline Mean & $2.12(0.785)$ & $3.13(0.860)$ & $5.31(1.38)$ & $1.28(0.334)$ & 12.18 & 24 & 0.76 \\
\hline
\end{tabular}

a Mean square error (MSE), degrees of freedom (df), and coefficient determination $\left(R^{2}\right)$ are presented for each regression model. Analyses were done for each replication, for the pooled data, and for the means across replication for each $T$ and $W$ combination.

${ }^{\mathrm{b}}$ Estimated parameters from the generalized Beta Model: $\alpha^{\prime}$ corresponds to the log-transformed $\alpha, \beta$ and $\gamma$ correspond to temperature effect, and $\delta$ corresponds to wetness duration. Numbers in parentheses correspond to the standard deviation. 
for internode severity, based on the magnitude of the correlation coefficients. There was an overall tendency for the model to underpredict disease intensity, especially for lesion numbers. This is evidenced by the intercept of the geometric mean regression equation for $Z$ as a function of $Y$ (equation 4) being larger than 0 (Figs. 6 and 7). However, with slopes generally less than 1, the degree of underprediction decreased with increasing predicted (and observed) infection. The intercepts were close to, or less than, 0 for the regression between $Z$ and $Y$ for internode severity (Figs. 6 and 7); therefore, there was no evidence of underprediction at low infection levels. However, the slopes were generally greater than 1 (e.g., 1.6 for Seyval in 2001), indicating that the underprediction increased with increasing level of infection.

Stepwise regression results indicated that predictions of disease in the field could not be consistently improved by using other environmental data (e.g., rain- fall amount) or using environmental data in forms other than that used in the controlled-environment-based model (e.g., linear relation between $Z$ and $W$ ). Of the eight combinations of cultivar, year, and diseased plant part measured (Catawba or Seyval $\times 2000$ or $2001 \times$ leaf or internode), in four cases it was not possible to improve predictions of disease over the use of the predictions from the controlledenvironment-based model $(Y)$ (O. Erincik, unpublished). That is, no other predictor variables were included in the empirical regression equation after $Y$ was included. The four cases were: Catawba in 2000 and 2001 for internode disease severity, Seyval in 2001 for lesions per leaf, and Seyval in 2001 for internode disease severity. In one case (Catawba in 2000 for lesions per leaf), mean temperature during the wetness event was a significant variable in the multiple regression model. In one case (Seyval in 2000 for internode disease severity), wetness duration was a significant variable. Finally, in two cases (Catawba in
2001 and Seyval in 2000 for lesions per leaf), the product of $Y$ and wetness duration was a significant variable. Thus, the most consistent way to predict disease for the inoculations in the field was to use wetness duration and mean temperature during the wetness event in equation 2 , with the model parameters from the data means in Tables 1 and 2.

\section{DISCUSSION}

Results from the controlled-environment studies indicate that wetness duration $(W)$ and temperature $(T)$ were significant environmental factors affecting leaf and cane infection of the grape cvs. Catawba and Seyval by $P$. viticola. The effect of $T$ and $W$ on leaf and cane infection can be seen clearly when the number of lesion on leaves $\left(Y_{\mathrm{L}}\right)$ or the disease severity on internodes $\left(Y_{\mathrm{I}}\right)$ are plotted against temperature at different wetness duration combinations (Figs. 1 and 2). The generalized Beta model described the effects of $T$ and $W$ on $Y_{\mathrm{L}}$ and $Y_{\mathrm{I}}$ for both cultivars under con-
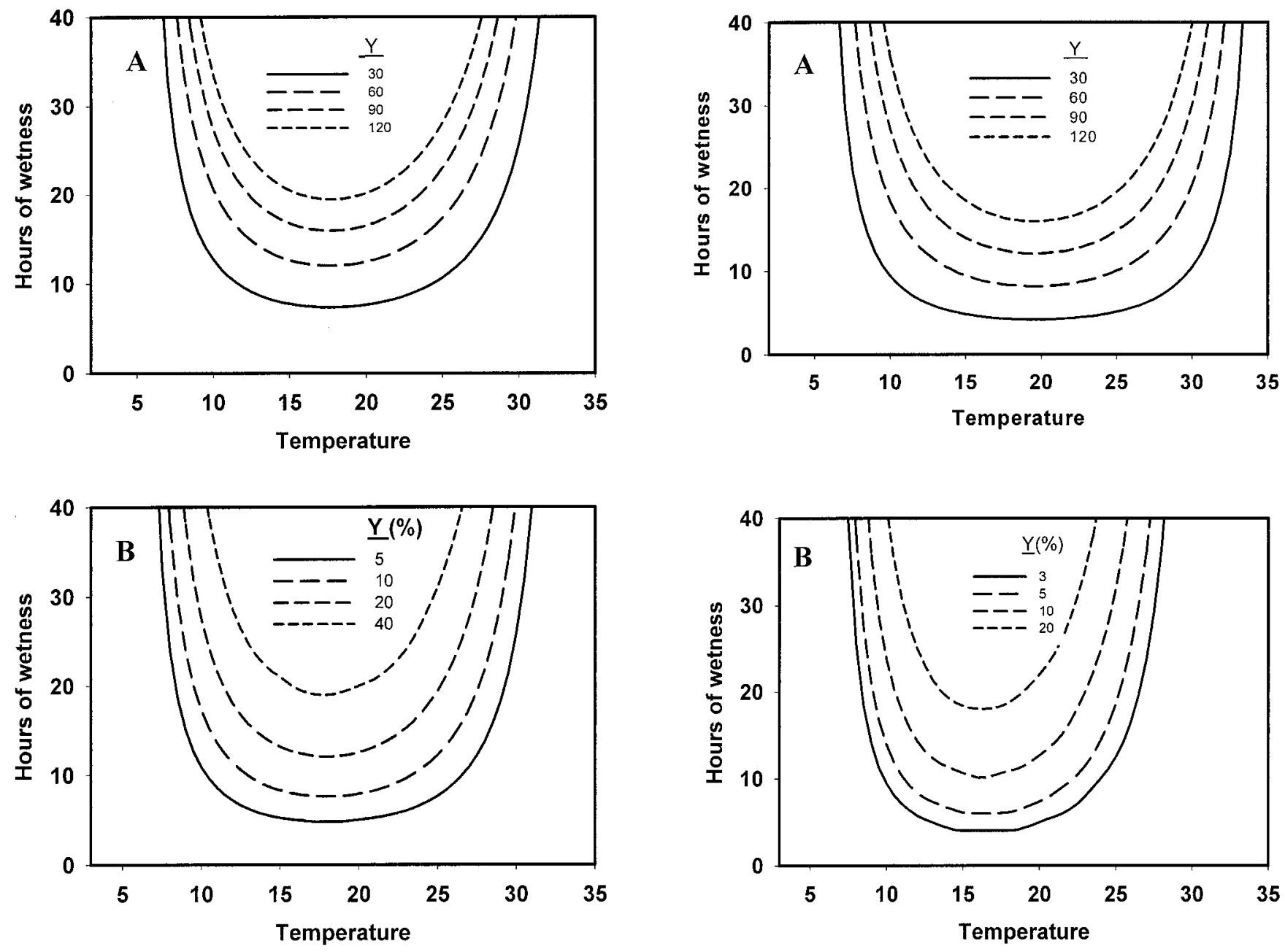

Fig. 4. Combinations of temperature and wetness durations required to predict $\mathbf{A}, 30,60,90$, and 120 lesions per leaf on 'Catawba' grapes; and B, 5, 10, 20, and 40\% disease severity on Catawba internodes. Curves were generated by using parameters from the generalized Beta Model in Table 1 for the mean data.

Fig. 5. Combinations of temperature and wetness durations required to predict $\mathbf{A}, 30,60,90$, and 120 lesions per leaf on 'Seyval' grapes; and $\mathbf{B}$, $3,5,10$, and $20 \%$ disease severity on Seyval grape internodes. Curves were generated by using parameters from the generalized Beta Model in Table 2 for the mean data. 
trolled environment conditions. The $R^{2}$ values obtained from the equation for mean $Y_{\mathrm{L}}$ and $Y_{\mathrm{I}}$ on Catawba were 90 and $85 \%$, respectively, and on Seyval were 88 and $76 \%$, respectively (Tables 1 and 2). These relatively high $R^{2}$ values indicate that a significant proportion of variability in $Y_{\mathrm{L}}$ and $Y_{\mathrm{I}}$ was accounted for by the independent variables of $T$ and $W$.

According to the data and model results, the effect of $T$ on $Y_{\mathrm{L}}$ and $Y_{\mathrm{I}}$ for both cultivars can be described by bell-shaped curves. This is expected based on results with other fungi $(6,13,30) . Y_{\mathrm{L}}$ and $Y_{\mathrm{I}}$ approached 0 at temperatures of 5 and $35^{\circ} \mathrm{C}$, the most extreme temperature tested in this study. $Y_{\mathrm{L}}$ and $Y_{\mathrm{I}}$ increased as $T$ increased to the optimum of approximately $18^{\circ} \mathrm{C}$ for Catawba and either about $16^{\circ} \mathrm{C}\left(Y_{\mathrm{I}}\right)$ or about $20^{\circ} \mathrm{C}\left(Y_{\mathrm{L}}\right)$ for Seyval. Above the optimum temperature, both $Y_{\mathrm{L}}$ and $Y_{\mathrm{I}}$ declined toward 0 . These optimum temperatures are lower than those reported for infection of $V$. vinifera grape by $P$. viticola in France by Bugaret (4). He showed that the optimum for leaf infection was between 23 and $25^{\circ} \mathrm{C}(4,5)$. Differences between our results and those reported by Bugaret may be explained partially by differences in cultivars or pathogen isolates. Both Catawba and Seyval are planted in the northern United States because they are known to be more tolerant of cold temperature (20). Bugaret (4), on the other hand, used a cultivar of $V$. vinifera, which is much more sensitive to cold temperature (20). It is possible that morphological differences between cultivars such as pubescence, cuticle thickness, epidermal cell wall morphology, or other morphological or physiological differences may influence the infection process; however, there is no information in the literature to support this speculation. Variation in the pathogen isolate also could be partially responsible for differences in results. In our study, an isolate that was collected from the northern United States was used; whereas, in Bugaret's study, the isolate was collected from southern France (Bordeaux).

Although Bugaret reported the optimum temperature to be 23 to $25^{\circ} \mathrm{C}$, he emphasized the importance of temperatures between 8 to $18^{\circ} \mathrm{C}$ for infection in his predictive model (5). He stated that the majority of leaf infections in the field occurred during or shortly after bud break and that the average temperature during this time usually ranged between 8 and $18^{\circ} \mathrm{C}$ (5). This temperature range early in the growing season (May) also is commonly observed in Ohio. The average temperature during each naturally occurring rain event during
May was determined for 3 years in Wooster. Average temperature ranged from 8.2 to $17.3,12.4$ to 18.9 , and 11.5 to $17.6^{\circ} \mathrm{C}$ in 1999, 2000, and 2001, respectively (O. Erincik, unpublished). Substantial infection occurred during several of these wetness events in 2000 and 2001, even when the mean temperature was considerably below the optimum (Figs. 6 and 7). Similar conclusions about the infection at low temperatures have been made previously. Willison et al. (29) and Hewitt and Pearson (14) indicated that the majority of grape vine infections by $P$. viticola occur early in the growing season, and they associated these early-season infections with low (but undefined) temperatures during this time. Hewitt and Pearson further speculated that the fungus was active only during low temperature and that, as temperature increased, the fungus became inactive, resulting in no or few infections later in the growing season (14).

Under controlled environmental conditions, lesions per leaf $\left(Y_{\mathrm{L}}\right)$ and internode severity $\left(Y_{\mathrm{I}}\right)$ for both grape cultivars increased consistently when $W$ increased up to at least 15 and usually $20 \mathrm{~h}$ (Figs. 1 and 2). The general increase in $Y_{\mathrm{L}}$ and $Y_{\mathrm{I}}$ with increase in $W$ could be described by nearly straight lines because estimated $\delta$ was fairly close to 1.0 (Tables 1 and 2). It has
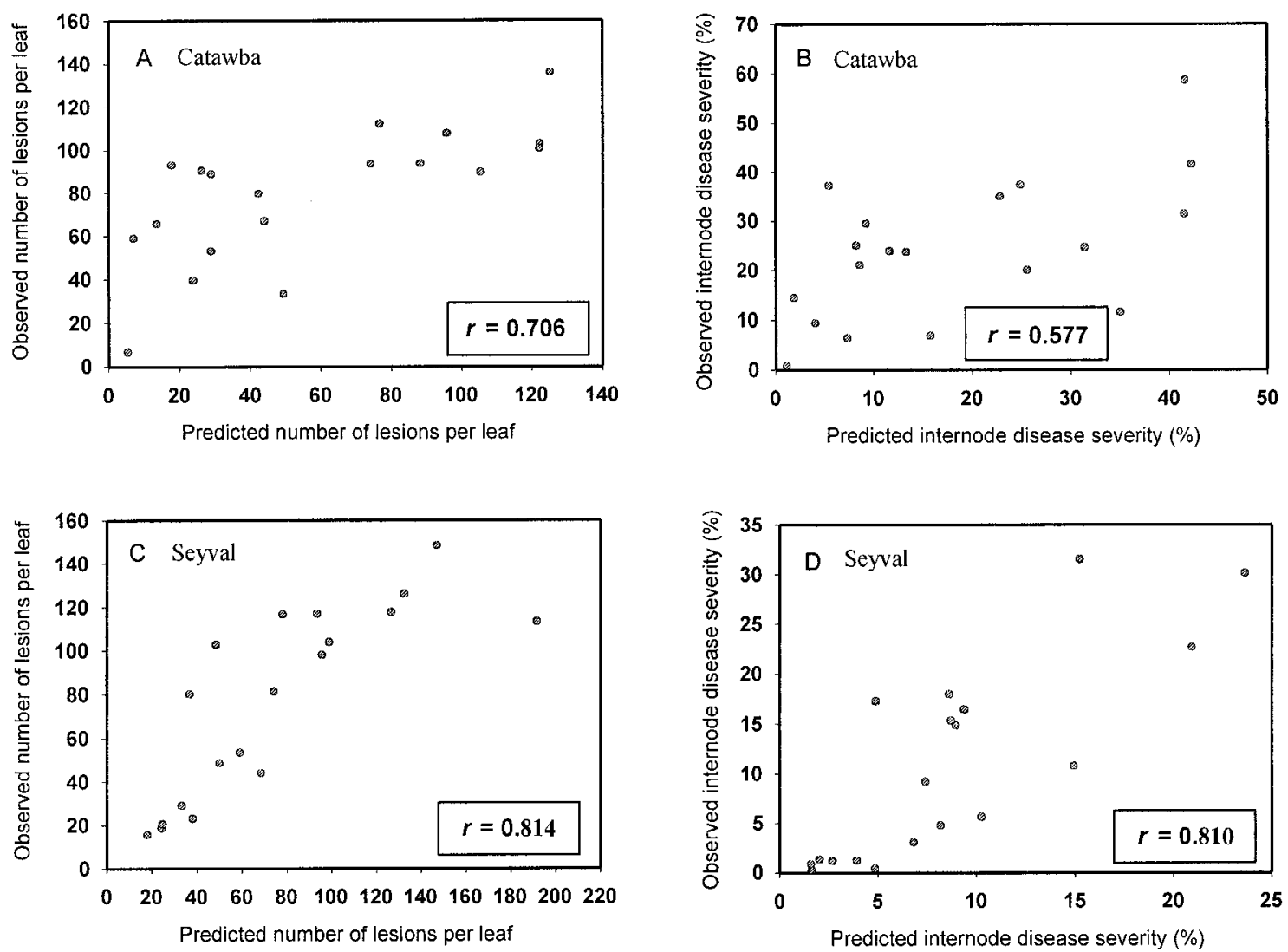

Fig. 6. Relationship between predicted leaf and internode infection based on the generalized Beta model ( $Y$ ), with parameter estimates in Tables 1 and 2 (for the mean data), and observed infection data on 'Catawba' and 'Seyval' vines (Z) inoculated with Phomopsis viticola in field studies during the 2000 growing season. A and $\mathbf{C}$, Observed number of lesions per leaf versus predicted numbers. B and $\mathbf{D}$, Observed internode disease severity versus predicted severity. Correlations are given as $r$ in the graphs. Geometric mean regression equations for $Z$ in the four graphs were $\mathbf{A}, 36.9+0.8 Y ; \mathbf{B}, 5.5+1.0 Y ; \mathbf{C}, 8.0$ $+0.9 Y$; and $\mathbf{D},-14.4+1.6 Y$. 
been well documented that free water on the plant surface is extremely important for germination of spores for many plantpathogenic fungi $(6,27,31)$, and the importance of free water for infection by $P$. viticola has been previously reported. Pine (23) showed that conidia of $P$. viticola did not germinate on dry wood, but germinated abundantly when the wood was moistened with water. Willison et al. (29) demonstrated that disease incidence and severity in years with heavy rains during May was significantly higher than years with dry weather during May.

Bugaret $(4,5)$ stated that $7.1 \mathrm{~h}$ of wetness were required in order for leaf infection to occur on $V$. vinifera at a temperature of $18^{\circ} \mathrm{C}$ in France; however, he did not describe the level of disease obtained at this temperature and wetness duration combination. We found similar results for wetness duration effects. For instance, at $18^{\circ} \mathrm{C}, 7.4 \mathrm{~h}$ of wetness were required for a prediction of 30 lesions per leaf on $\mathrm{Ca}$ tawba (Fig. 4A), a relatively low number based on the inoculation method used in this study (Fig. 1). Bugaret further reported that at least $4 \mathrm{~h}$ of wetness duration was required to obtain leaf infection on $V$. vinifera at temperatures of 23 and $25^{\circ} \mathrm{C}$, the optimum temperature in his study. In our study, the time required for a given level of leaf infection on Seyval was found to be shorter than that on Catawba (Fig. 5), suggesting that Seyval was more susceptible than Catawba. For instance, the required wetness duration for a prediction of 60 lesions per leaf on Seyval at $20^{\circ} \mathrm{C}$ (optimum in our study) was $8.2 \mathrm{~h}$ (Fig. 5A). For Catawba, $12.4 \mathrm{~h}$ of wetness was required in the model for a model prediction of 60 lesions per leaf at the same temperature (Fig. 4A).

Field validation studies over 2 years indicated that the generalized Beta model (equation 3), with parameters determined from the controlled-environment studies, generally predicted leaf and cane infection on both cultivars over a wide range of wetness durations and temperatures measured in the field. Typically, an increase in predicted infection was associated with an increase in observed infection, although there was variability of observed infection at any given level of predicted infection, and there was a tendency for predictions to be a little lower than observations. Systematic under (or over) prediction is not of concern in applications of models of this type, because one can make corrections easily by fitting equation 4 (with no $X$ variables) to the data and using predicted $Z$ as the measure of disease intensity at a specific combination of temperature and wetness duration rather than using $Y$ (Figs. 6 and 7).

There are several possible reasons for the observed variability and underprediction. First, the model was not a perfect fit of the controlled-environment data $\left(R^{2} \approx\right.$ $0.80)$, so there is no expectation that the model would produce exact prediction of infection in the field. This is the equivalent of a "measurement error" problem (7), which is known to increase variability and produce bias in the predictions. Second, it is possible that leaf and internode susceptibility varied over the season in response to changing environmental conditions $(12,14)$. Third, environmental factors other than those considered here may affect infection, and environmental factors were not controlled in the field (3). Although rainfall was not related to field infection, based on the stepwise regression results, relative humidity was not measured or evaluated in this study. Fourth, the ranges of wetness durations in the field were somewhat larger than assessed in the controlled-environment study. In particular, there were a few inoculation events with wetness durations below $5 \mathrm{~h}$ or above $20 \mathrm{~h}$. However, observed and predicted disease intensity were always very low (or zero) at the short wetness durations and very high at the long wetness durations. Finally, temperature was not
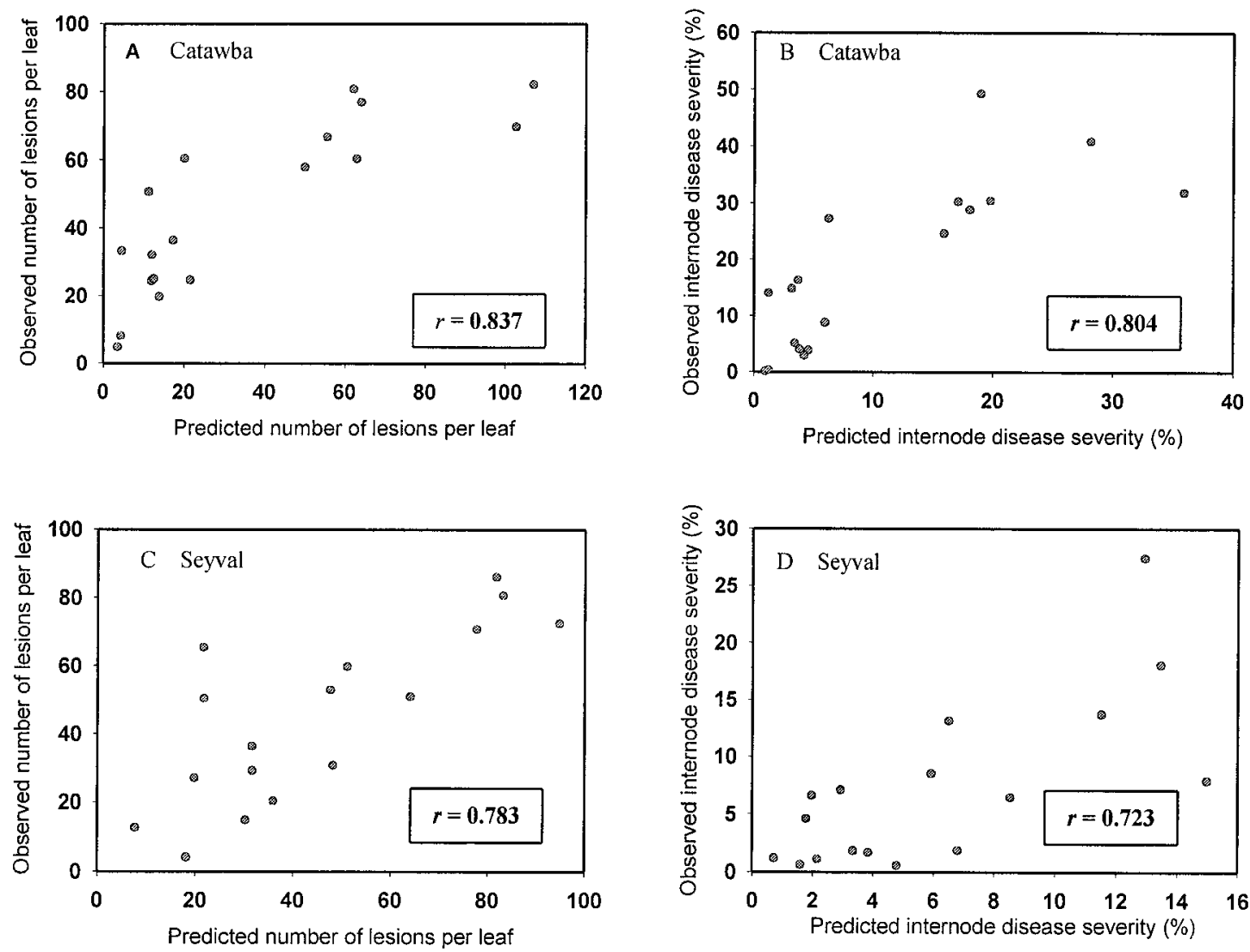

Fig. 7. Relationship between predicted leaf and internode infection based on the generalized Beta model ( $Y$ ), with parameter estimates in Tables 1 and 2 (for the mean data), and observed infection data on 'Catawba' and 'Seyval' vines ( $Z$ ) inoculated with Phomopsis viticola in field studies during the 2001 growing season. A and $\mathbf{C}$, Observed number of lesions per leaf versus predicted numbers. $\mathbf{B}$ and $\mathbf{D}$, Observed internode disease severity versus predicted severity. Correlations are given as $r$ in the graphs. Geometric mean regression equations for $Z$ in the four graphs were: $\mathbf{A}, 18.7+0.8 Y$; $\mathbf{B},-9.2+1.4 Y$; $\mathbf{C}$, $2.2+1.0 Y$; and $\mathbf{D},-9+1.6 Y$. 
constant during individual wetness periods in the field, and it is known that variable temperature can affect mean biological responses to temperature in comparison to responses to constant temperature (28). However, the effect of nonconstant temperature on results may be small in this study. In particular, based on the method described in Scherm and van Bruggen (28), predictions of lesion numbers and internode disease severity for variable temperature differed from the predictions for a constant temperature by less than an average $2 \%$ (L. V. Madden, unpublished).

The use of disease forecasting or warning systems for timing of fungicide applications for controlling several plant diseases in Ohio has been demonstrated $(9,10,19)$. Often, the number of fungicide applications can be reduced while obtaining control equal to that obtained with a greater number of applications (i.e., with a full-season fungicide program). Forecasting systems have been developed based on environmental parameters and regression models similar to those described in this study $(7,9,10,16-19)$. Some of these are based on the use of protectant fungicides and some use curative fungicides. The model developed in this study currently is being evaluated in field trials to determine its effectiveness in timing fungicide applications for control of Phomopsis cane and leaf blight. Although an accurate warning system will be most useful once fungicides with curative or kickback activity are labeled for Phomopsis control in grapes, the model also should be useful to simply identify periods with high probability of infection in order to schedule the application of protectant fungicides. Even if the model is never used in a formal warning system, results add a great deal to our knowledge of this disease. In particular, results indicate that infection occurs over a wide temperature range with wetness durations that are typical for Ohio, especially at temperatures less than identified for France.

\section{LITERATURE CITED}

1. Analytis, S. 1977. Über die relation zwischen biologischer entwicklung und temperatur bei phytopathogene pilzen. On the relation between temperature and biological response of some plant pathogenic fungi. Phytopathol. Z. 90:64-76

2. Anderson, H. W., and Colby, A. S. 1943. Dead arm disease of grape in Illinois. Plant Dis. Rep. 27:245-246.

3. Aust, H. J., and Kranz, J. 1988. Experiment and procedures in epidemiological field studies. Pages 7-16 in: Experimental Techniques in Plant Disease Epidemiology. J. Kranz and J. Rotem, eds. Springer-Verlag. New York.

4. Bugaret, Y. 1984. L'Excoriose de la vigne: Recherches sur le Phomopsis viticola Sacc., nouvelles possibilities de lutte. Ph.D. thesis. University of Bordeaux, Bordeaux, France.

5. Bugaret, Y. 1986. New information on epidemiology of excoriation and their effects for control. Donnees nouvelles sur l'epidemiologie de l'excoriose et leurs consequences pour la lutte. Phytoma 375:36-41.

6. Bulger, M., Ellis, M. A., and Madden, L. V. 1987. Influence of temperature and wetness duration on infection of strawberry flowers by Botrytis cinerea and disease incidence of fruit originating from infected flowers. Phytopathology 77:1225-1230.

7. Campbell, C. L., and Madden, L. V. 1990. Introduction to Plant Disease Epidemiology. Wiley-Interscience Publication, New York.

8. Eichhorn, K. W., and Lorenz, D. H. 1977. Phänologishche Enwicklungsstadien der Rebe. Nachrichtenbl. Dtsch. Pflanzenschutzdienstes (Braunschweig) 29:119-120.

9. Ellis, M. A., Madden, L. V., and Wilson, L. L. 1984. Evaluation of an electronic apple scab predictor for scheduling fungicides with curative activity. Plant Dis. 68:1055-1057.

10. Ellis, M.A., Madden, L. V., and Wilson, L. L. 1986. Electronic grape black rot predictor for scheduling fungicides with curative activity. Plant Dis. 70:938-940.

11. Erincik, O., Madden, L. V., Ferree, D. C., and Ellis, M. A. 2001. Effect of growth stage on susceptibility of grape berry and rachis tissues to infection by Phomopsis viticola. Plant Dis. 85:517-520.

12. Gregory, C. T. 1913. A rot of grapes caused by Cryptosporella viticola. Phytopathology 3:2023.

13. Grove, G. G., Madden, L. V., Ellis, M. A., and Schmitthenner, A. F. 1985. Influence of temperature and wetness duration on infection of immature starberry fruit by Phytophthora cactorum. Phytopathology 75:165-169.

14. Hewitt, W. B., and Pearson, R. C. 1990. Phomopsis cane and leaf spot. Pages 17-18 in: Compendium of Grape Disease. R. C. Pearson and A. Goheen, eds. The American Phytopathological Society Press, St. Paul, MN.

15. Horsfall, J. G., and Barratt, R. W. 1945. An improved grading system for measuring plant disease. (Abstr.) Phytopathology 35:655.

16. Huber, L., and Gillespie, T. J. 1992. Modeling leaf wetness in relation to plant disease epidemiology. Annu. Rev. Phytopathol. 30:553577.

17. Jones, A. L., Lillevik, S. L., Fisher, P. D., and Stebbins, T. C. 1980. A microcomputer-based instrument to predict primary apple scab infection periods. Plant Dis. 64:69-72.

18. Madden, L. V., Ellis, M. A. 1988. How to develop plant disease forecasters. Pages 191208 in: Experimental Techniques in Plant Disease Epidemiology. Springer-Verlag, New York.

19. Madden, L. V., Ellis, M. A., Lalancette, N., Hughes, G., and Wilson, L. L. 2000. Evaluation of a disease warning system for downy mildew of grapes. Plant Dis. 84:549-554.

20. Mullins, M. G., Bouquet, A., and Williams, L. E. 1992. Biology of the grapevine. Cambridge University Press, New York.

21. Pearson, R. C., and Goheen, C. A.1990. Compendium of Grape Diseases. American Phytopathological Society Press. St. Paul, MN.

22. Pine, T. S. 1958. Etiology of the dead arm disease of grapevines. Phytopathology 48:192196.

23. Pine, T. S. 1959. Development of the grape dead-arm disease. Phytopathology 49:738743.

24. Pscheidt, J. W., and Pearson, R. C. 1989. Time of infection and control of Phomopsis fruit rot of grape. Plant Dis. 73:829-833.

25. Reddick, D. 1909. Necrosis of the grape vine. Cornell Univ. Agric. Exp. Stn. Geneva N. Y Bull. 263:323-343.

26. Reddick, D. 1914. Dead arm disease of grapes. N. Y. State Agric. Exp. Stn. Geneva N. Y. Bull. 389:463-490

27. Rotem, J., and Palti, J. 1969. Irrigation and plant diseases. Annu. Rev. Phytopathol. 7:267-288

28. Scherm, H., and van Bruggen, A. H. C. 1994. Effects of fluctuating temperatures on the latent period of lettuce downy mildew (Bremia lactucae). Phytopathology 84:853-859.

29. Willison, R. S., Chamberlain, G. C., Townsend, J. L., and de Ronde, J. H. 1965. Epidemiology and control of dead-arm of grapes. Can. J. Bot. 43:901-914.

30. Wilson, L. L., Madden, L. V., and Ellis, M. A. 1990. Influence of temperature and wetness duration on infection of immature and mature strawberry fruit by Colletotrichum acutatum. Phytopathology 80:111-116.

31. Yarwood, C. E. 1978. Water and the infection process. Pages 141-173 in: Water Deficits and Plant Growth: Water and Plant Disease. T. T. Kozlowski, ed. Academic Press, London. 